\title{
Coupled Analysis of Heat Transfer and Deformation in Equal Channel Angular Pressing of Al and Steel
}

\author{
Pham Quang ${ }^{1}$, A. Krishnaiah ${ }^{2}$, Sun Ig Hong ${ }^{3}$ and Hyoung Seop Kim ${ }^{4}$,* \\ ${ }^{1}$ Faculty of Material Science and Technology, Hanoi University of Technology, Hanoi, Vietnam \\ ${ }^{2}$ Department of Mechanical Engineering, University College of Engineering (Autonomous), \\ Osmania University, Hyderabad-500 007, India \\ ${ }^{3}$ Department of Nano Materials Engineering, Chungnam National University, Daejeon 305-764, Korea \\ ${ }^{4}$ Department of Materials Science and Engineering, POSTECH, Pohang 790-784, Korea
}

In the present paper, the heat transfer and plastic deformation during the equal channel angular pressing of $\mathrm{Al}$ alloy and steel were numerically analyzed. The finite element simulations were carried out at various pressing speeds $v=0.18,1.8$, and $18 \mathrm{~mm} / \mathrm{s}$, and the temperature and plastic strain distributions were investigated. It is concluded that the pressing speed is the most important processing parameter in rising temperature. Temperature rise in steel is higher than that in $\mathrm{Al}$ alloy due to the combined effect of high strength (heat generation effect) and low thermal diffusivity (heat release effect) in steel. [doi:10.2320/matertrans.MD200823]

(Received September 29, 2008; Accepted October 31, 2008; Published December 25, 2008)

Keywords: equal channel angular pressing, severe plastic deformation, finite element method, heat transfer analysis

\section{Introduction}

Equal channel angular pressing (ECAP) is an attractive severe plastic deformation (SPD) technique for the development of ultrafine grained (UFG) microstructures in metals and alloys by imposing large strain, without changing the cross-sectional dimensions of a billet. ${ }^{1-4)}$ The production of a UFG microstructure using ECAP results from the intense plastic strains introduced in the metallic material that drives the recovery/recrystallization in the strained materials. A schematic of the ECAP die setup is shown in Fig. 1. The ECAP die consists of two (entry and exit) equal channels that intersect at an angle usually between $90^{\circ}$ and $135^{\circ}$. The main advantage of the ECAP process is that the process can be repeated several times using the same specimen to impose large plastic strains leading to the production of UFG microstructures because of its capability of maintaining the net dimensions of the workpiece.

Numerous experimental and simulation works on the deformation behavior of workpiece in ECAP have been presented recently. Most of the studies on ECAP published to date are concerned mainly with the ability to produce UFG microstructures and the unique deformation geometry of the workpiece in ECAP. The evolution of the microstructures and physical properties of the SPD processed material is related directly to the histories of plastic deformation and temperature, and hence the understanding of the phenomenon associated with strain and temperature developments is very important for the successful manipulation of ECAP process. There are many publications on the deformation behavior during ECAP by using various numerical methods. However, only a few activities on the analysis of temperature and heat transfer have been reported, in comparison to those of deformation and microstructural behavior. To the best of the authors' knowledge, nobody attempted the finite element method (FEM) simulation of ECAP process to predict the

*Corresponding author, E-mail: hskim@postech.ac.kr

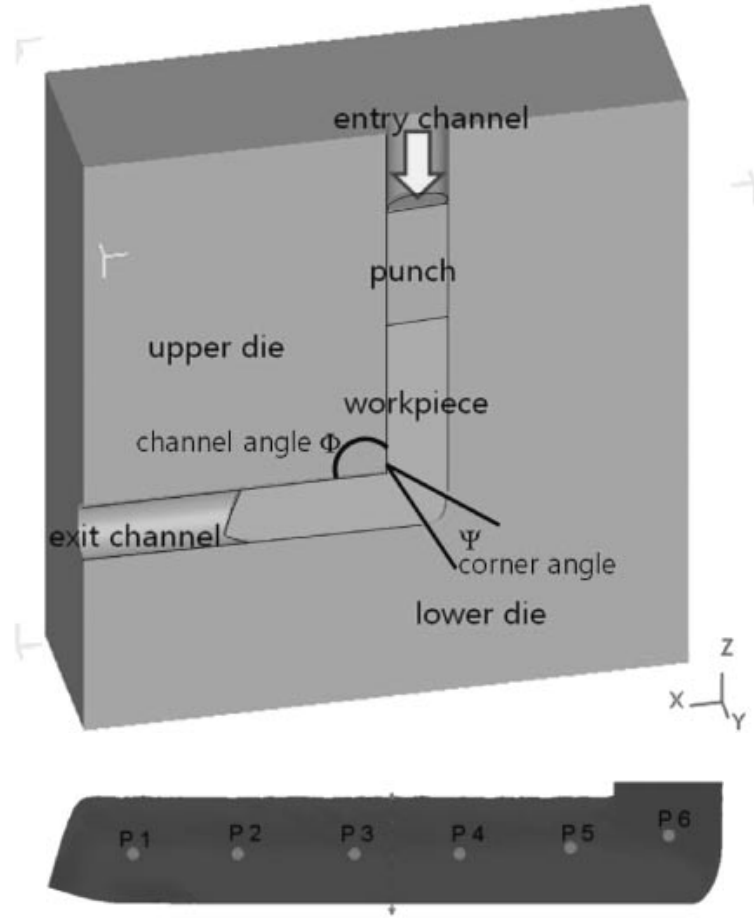

Fig. 1 Die and workpiece geometry of ECAP.

temperature rise. Nishida et al. $^{5)}$ conducted an experimental investigation on two $\mathrm{Al}$ alloys, one $\mathrm{Mg}$ alloy and a metal matrix composite to measure the billet temperature rise during ECAP at a constant pressing speed. Yamaguchi et al. ${ }^{6)}$ investigated the significance of adiabatic heating in ECAP on $\mathrm{Al}$ alloys. Kim made heat transfer analyses using a lumped analytical method in $\mathrm{ECAP}^{7)}$ and the finite volume method $(\mathrm{FVM})$ in equal channel multi-angular pressing $(\mathrm{ECMAP})^{8)}$ to predict the temperature rises.

Practically, the workpiece temperature in ECAP is controlled through the preheating of the workpiece. However, the exact workpiece temperature during an ECAP operation may be significantly above the preheating temper- 
ature due to the heat generated by the plastic work. It is therefore necessary to estimate the actual workpiece temperature during the ECAP for a precise control of recovery/ recrystallization, and hence of the grain size. The temperature rise during the ECAP is considered to depend on both the sample material and the deformation rate (pressing speed). In the present study, finite element analyses were conducted to analyze the temperature histories and distributions in the workpiece during the ECAP of Al alloy and steel. In order to better understand both temperature distribution and strain characteristics, and in order to determine the pressing load during the processing of $\mathrm{Al}$ alloy and steel, FEM simulations were carried out for ECAP at room temperature under different pressing speeds.

\section{Finite Element Analyses}

Figure 1 represents the schematic of ECAP process, showing die, punch, workpiece, and important design angles (channel angle $\Phi$ and corner angle $\psi$ ). The points with numbers show reference positions in the workpiece along longitudinal direction for tracking thermal history. A coupled deformation and heat transfer FEM simulation of ECAP was carried out using the rigid-plastic commercial FEM code DEFORM-3D ver. 6.1. ${ }^{9)}$ It should be noted that a twodimensional simulation cannot correctly reproduce the temperature responses because heat transfers along the normal to the entry and exit channel directions as well as parallel to the channel directions, although two-dimensional deformation simulation is acceptable due to the plan strain condition of deformation in ECAP. A typical value of friction factor $m=0.1$ for cold metal forming was considered between the inner surfaces of the die channels and the outer surface of the workpiece. The simulations were carried out at three different punch speeds; $v=0.18,1.8$, and $18 \mathrm{~mm} / \mathrm{s}$. The numbers of initial elements and nodes of an 8-node hexagonal element were 45,105 and 10,315, respectively. This number of elements was found to be sufficient to express the local deformation and heat of the strain rate insensitive materials through the calculations with varying the number of elements in DEFORM-3D.

The simulations were carried out using a die with die channel angle $\Phi=90^{\circ}$ and outer corner angle $\psi=20^{\circ}$ for single pass. Die and punch were modeled with rigid parts. Cylindrical specimen with dimensions of diameter $10 \mathrm{~mm} \times$ height $60 \mathrm{~mm}$ was used for all simulations. The stress-strain curves of the materials (AISI1015 steel and Al 6063 alloy) at various temperatures supported by the DEFORM database ${ }^{9)}$ are shown in Fig. 2, where strain hardening and temperature dependent flow curves are clearly observed. In the present study, the influence of processing speeds during the ECAP of $\mathrm{Al}$ alloy and steel in terms of temperature distribution was also investigated. The mechanical and thermal constants of $\mathrm{Al}$ alloy and steel used in ECAP simulation are shown in Table 1.

\section{Results and Discussion}

The simulated equivalent strain distribution fringes with deformed geometries for $\mathrm{Al}$ alloy and steel are represented in

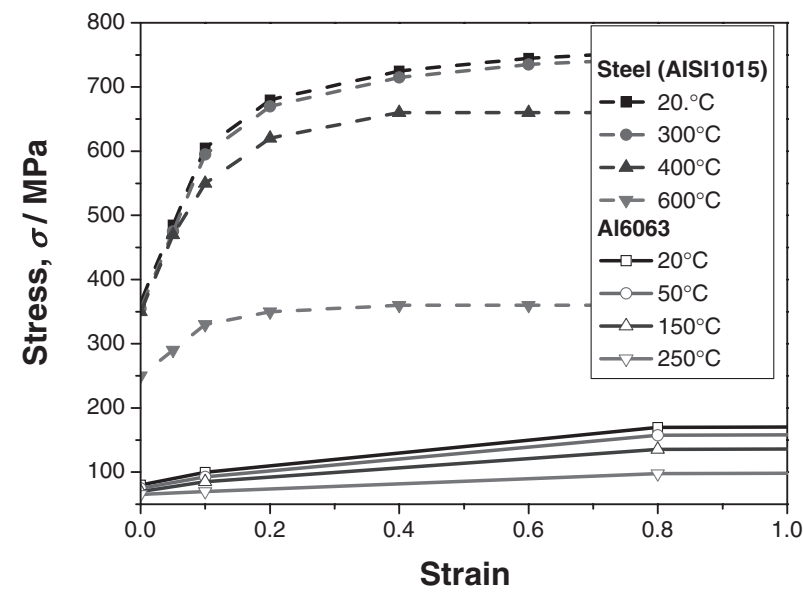

Fig. 2 Stress-strain curves of Al alloy and steel used in FEM simulations.

Table 1 Mechanical and thermal constants of Al alloy and steel used in ECAP simulation.

\begin{tabular}{|c|c|c|c|}
\hline \multicolumn{2}{|c|}{ Properties } & Aluminum & Steel \\
\hline \multicolumn{2}{|c|}{ Young's modulus E, GPa } & 68.9 & 210 \\
\hline \multicolumn{2}{|l|}{ Poisson's ratio } & 0.33 & 0.3 \\
\hline \multicolumn{2}{|c|}{ Density, $\mathrm{kg} / \mathrm{m}^{3}$} & 2700 & 7833.4 \\
\hline \multicolumn{2}{|c|}{ Coefficient of thermal, ${ }^{\circ} \mathrm{C}^{-1}$} & $22 \times 10^{-6}$ & $12 \times 10^{-6}$ \\
\hline \multicolumn{4}{|c|}{ Steel (AISI $1015,20-1100^{\circ} \mathrm{C}$ ) } \\
\hline $\begin{array}{l}\text { Temperature, } \\
{ }^{\circ} \mathrm{C} \\
\end{array}$ & $\begin{array}{l}\text { Thermal conductivity, } \\
\mathrm{W} /(\mathrm{m} \cdot \mathrm{K})\end{array}$ & \multicolumn{2}{|c|}{ Specific heat, $\mathrm{J} /\left(\mathrm{kg} \cdot{ }^{\circ} \mathrm{C}\right.$} \\
\hline 100 & 50.708 & \multicolumn{2}{|c|}{3.809} \\
\hline 199 & 48.112 & \multicolumn{2}{|c|}{4.039} \\
\hline 299 & 45.689 & \multicolumn{2}{|c|}{3.125} \\
\hline 399 & 41.718 & \multicolumn{2}{|c|}{4.598} \\
\hline 499 & 38.279 & \multicolumn{2}{|c|}{5.090} \\
\hline \multicolumn{4}{|c|}{ Aluminum $\left(\mathrm{Al} 6063,20-250^{\circ} \mathrm{C}\right)$} \\
\hline $20-250$ & 180.2 & \multicolumn{2}{|c|}{2.433} \\
\hline
\end{tabular}

1.200

0.807

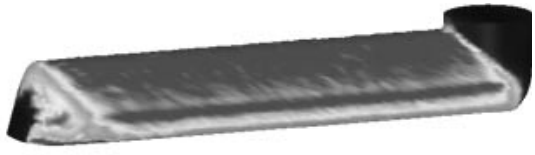

Al

0.413

0.020

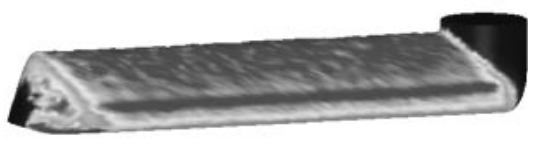

Steel

Fig. 3 Equivalent strain distributions in $\mathrm{Al}$ alloy and steel pressed at speed of $v=1.8 \mathrm{~mm} / \mathrm{sec}$

Fig. 3. The strain distributions are almost the same for $\mathrm{Al}$ and steel because the die geometries are the same, although the material properties and thermal responses are different. Strains are the same in all cases of ram speeds $(v=0.18,1.8$ and $18 \mathrm{~mm} / \mathrm{s}$ ). The independence of strain and geometry with pressing speed is due to the strain rate insensitivity of flow behavior used for the simulations. The developed strain value 


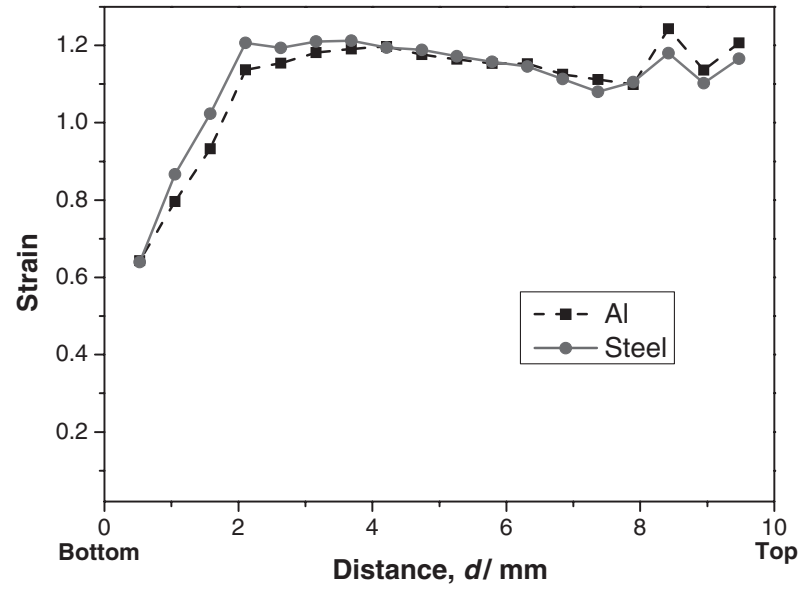

Fig. 4 Path plot in $\mathrm{Al}$ alloy and steel pressed at speed of $v=1.8 \mathrm{~mm} / \mathrm{sec}$.

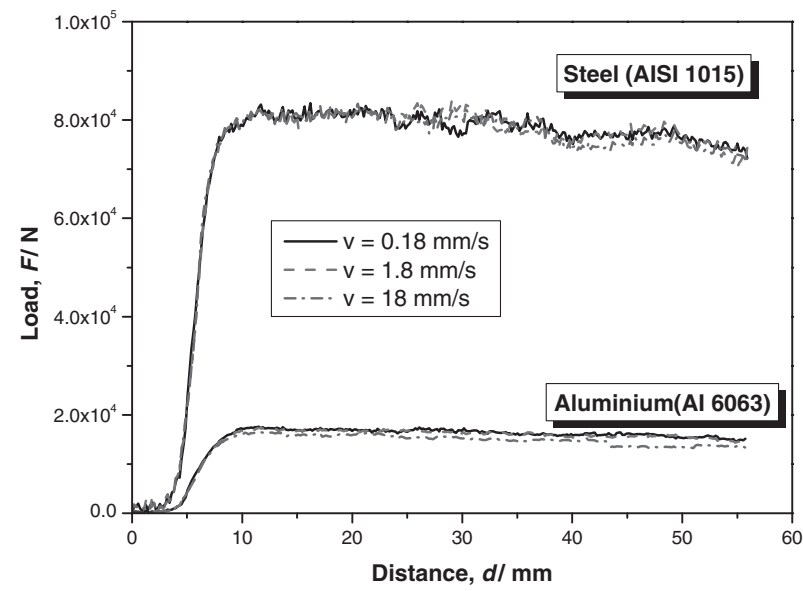

Fig. 5 Load-time plot of Al alloy and steel at various pressing speeds.

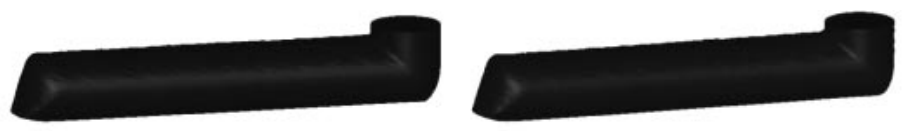

(a)

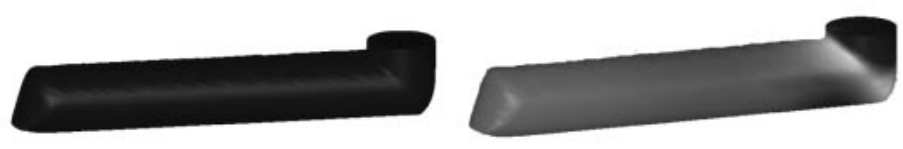

(b)
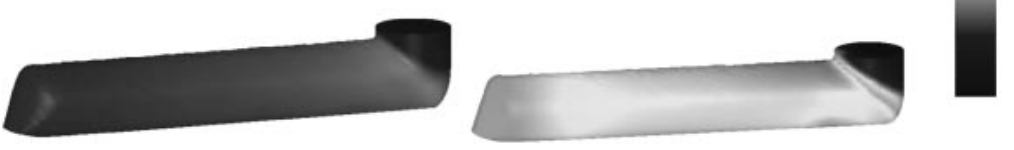

25.0

(c)

Fig. 6 Temperature distributions in Al alloy and steel pressed at speeds of (a) $v=0.18 \mathrm{~mm} / \mathrm{sec} ;$ (b) $v=1.8 \mathrm{~mm} / \mathrm{sec}$; and (c) $v=$ $18 \mathrm{~mm} / \mathrm{sec}$.

$(\sim 1)$ in the middle region is in good agreement with results of analytical solution value ${ }^{7)}$ after ECAP by using $\Phi=90^{\circ}$ and angle $\psi=20^{\circ}$ for one pass. Strain at the inner corner is higher than that in the outer corner in the main shear deforming zone. The low strain in the bottom region is due to the effect of round corner and strain hardening characteristic in the flow behavior of the material. ${ }^{10)}$ The strain uniformity can be observed in the middle (steady state region) of the sample along the exit channel direction of the workpiece. Comparing with the other regions, the equivalent plastic strains are much more uniform and larger along the exit channel direction in this steady deformation region. The strain distribution along the radial (width) direction in the steady region is shown in Fig. 4. Due to the strain hardening effect, ${ }^{10)}$ strain in the bottom region is smaller than the other upper region.

Figure 5 shows the load-time history plots at various pressing speeds. The steel exhibited a high pressing load $(80 \mathrm{kN})$ as compared to Al alloy $(16 \mathrm{kN})$ in all cases of pressing speed, because of the intrinsic harder properties of steel than $\mathrm{Al}$ alloy. It should be noted that stress levels in steel is about 5 times of those of $\mathrm{Al}$ at the same strain level as shown in Fig. 2, which matches well with the ratio of forming loads in $\mathrm{Al}$ and steel as depicted in Fig. 5.

The temperature contours of $\mathrm{Al}$ alloy and steel are plotted in Fig. 6, for different pressing speeds. The temperature increased with the increasing pressing speed, contrary to the results of strain which are insensitive to the pressing speed. The internal heat generation due to the plastic work within the main deforming zone of the specimen is transferred to the ECAP die and the remaining energy is stored. The internal heat generation due to the plastic work is usually around $90 \%$ of the work of plastic deformation. ${ }^{11)}$ According to the author's analytical derivation, ${ }^{7)}$ the temperature rise $\Delta T$ of the workpiece is

$$
\Delta T=\frac{0.9 \sigma \varepsilon+0.5 m(\sigma / \sqrt{3}) u \frac{A}{V} \Delta t}{\rho C+\frac{A}{V} h \Delta t},
$$

where $\sigma, \varepsilon, \rho, C, V, A, \Delta t, m, u$ and $h$ denote stress, strain, the density of the material, its heat capacity, the volume of the calculation domain (i.e. of the main deforming zone), the outer surface area of the domain contacting the die, the dwell 


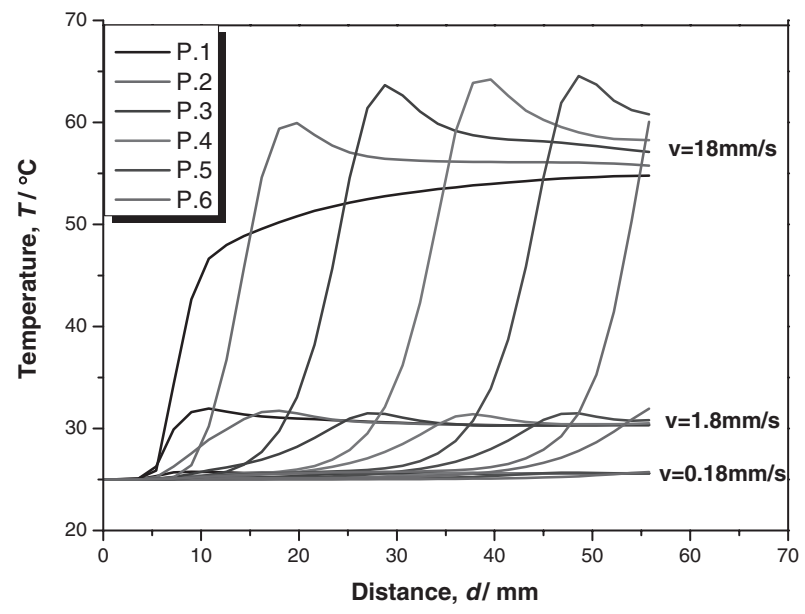

Al

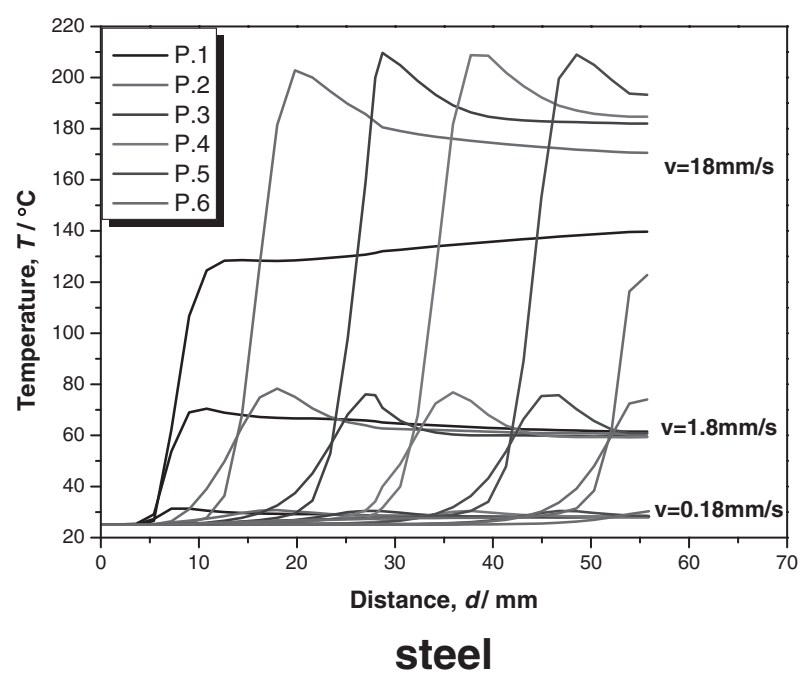

Fig. 7 Temperature history in Al alloy and steel.

time of the domain within the deforming zone, friction factor, punch velocity, and the heat transfer coefficient between the workpiece and the die, respectively. Hence, the temperature increment in steel is higher than that in $\mathrm{Al}$ due to the higher deformation heat, all other conditions being the same. Figures 6 and 7 show the effect of the pressing velocity, the most important factor governing the temperature rise. With increasing pressing velocity, temperature rises in both $\mathrm{Al}$ and steel, due to the lack of time for the heat release from the workpiece to the die. Figure 7 also show overshooting and stabilizing stages, which cannot be observed in the analytical solution. ${ }^{7)}$ This overshoot is smaller in steel having lower thermal diffusivity (thermal conductivity/density $\times$ heat capacity) that in $\mathrm{Al}$ alloy. The variation of temperature at six points has been monitored by the particle tracking method. Figure 7 shows that for low pressing speeds ( $v=0.18$ and $1.8 \mathrm{~mm} / \mathrm{s}$ ) there is no temperature difference among the six points during the ECAP of Al alloy and steel, but at higher pressing speeds $(v=18 \mathrm{~mm} / \mathrm{s})$ there is a notable temperature rise between the six points. The temperature of $\mathrm{Al}$ increased in the range of $11.7^{\circ} \mathrm{C}-18^{\circ} \mathrm{C}$ for low pressing speeds and an average of $40^{\circ} \mathrm{C}$ for higher pressing speed. On the other hand, temperature rise in steel is high $\left(\sim 150^{\circ} \mathrm{C}\right)$ especially a high pressing speed, which is the combined effect of high strength (heat generation effect) and low thermal diffusivity (heat release effect).

\section{Conclusions}

The influence of pressing speed on the deformation temperature of $\mathrm{Al}$ alloy and steel during the equal channel angular pressing was studied by the coupled heat-deformation 3D-finite element method. The homogeneous plastic deformation is obtained in the middle of the sample for all processing speeds. For the high speed condition $(v=18 \mathrm{~mm} /$ s) sample pressed during the ECAP of steel, higher temperature rise obtained is compared to the case of low pressing speed. Due to the deformation induced heat release, the temperature rise during the ECAP with high ram speed, especially for high strength materials, can be as large as to raise the workpiece temperature above the recovery temperature or the grain growth temperature. Temperature rise in steel is higher than that in $\mathrm{Al}$ alloy due to the combined effect of high strength (heat generation effect) and low thermal diffusivity (heat release effect) in steel. The heat transfer analysis presented in this study can be used as an informative method to control the ECAP process parameters.

\section{Acknowledgments}

This research was supported by a grant from the Center for Advanced Materials Processing (CAMP) of the 21st Century Frontier R\&D Program funded by the Ministry of Science and Technology, Republic of Korea.

\section{REFERENCES}

1) V. M. Segal: Mater. Sci. Eng. A 197 (1995) 157

2) R. Z. Valiev: Metall. Mater. Int. 7 (2001) 413.

3) I. V. Alexandrov: Metall. Mater. Int. 7 (2001) 565.

4) Y. Fukuda, K. Oh-ishi, Z. Horita and T. G. Langdon: Acta Mater. 50 (2002) 1359

5) Y. Nishida, T. Ando, M. Nagase, S. Lim, I. Shigematsu and A. Watazu: Scr. Mater. 46 (2002) 211.

6) D. Yamaguchi, Z. Horita, M. Nemoto and T. G. Langdon: Scr. Mater. 41 (1999) 791

7) H. S. Kim: Mater. Trans. 42 (2001) 536-538.

8) H. S. Kim: Mater. Sci. Eng. A (2008) in press.

9) SFTC, DEFORM-3D ver. 6.1.

10) H. S. Kim, M. H. Seo and S. I. Hong: Mater. Sci. Eng. 291A (2000) 86.

11) S. Kobayashi, S.-I. Oh and T. Altan: Metal Forming and the FiniteElement Method, (Oxford University Press, Oxford, 1989) pp. 228229. 